\title{
The Potentially Deleterious Impact of Muscle Activity on Gamma Band Inferences
}

\author{
Alexander J Shackman*,I \\ 'Laboratory for Affective Neuroscience, Waisman Laboratory for Brain Imaging and Behavior, University of Wisconsin-Madison, Madison, \\ WI, USA
}

Neuropsychopharmacology (2010) 35, 847; doi:I0.1038/npp.2009.173

Sir,

In an exciting study recently reported in Neuropsychopharmacology, Barr et al (2009) found that the application of high-frequency repetitive transcranial magnetic stimulation (TMS) amplified the gamma band $(30-50 \mathrm{~Hz})$ brain electrical activity associated with performance of an $n$-back working memory (WM) task.

As a precursor to the analyses of TMS effects, WM-related gamma activity was examined. Critically, gamma activity during the delay period showed a significant effect of load (2-back $>1$-back $>0$-back) in an a priori frontal cluster of electrodes (AF3/4, F3/4, F5/6, F1/2, Fz). This effect is consistent with observations made using hemodynamic techniques and intracranial measures of gamma activity (eg, Axmacher et al, 2008).

But are load-dependent changes in gamma activity actually generated in the brain or are they simply an artifact of changes in cranial muscle tension? It is clear that the facial muscles, in particular, are exquisitely sensitive to a variety of cognitive and affective processes, including cognitive load (Shackman et al, 2009). The electromyographic (EMG) activity generated by these muscles is present at virtually all frequencies, extending as low as $2 \mathrm{~Hz}$, and can be detected across the entire scalp (Shackman et al, 2009).

Unfortunately, it is difficult to judge whether the loaddependent gamma band effects reported by Barr et al are myogenic because the key figures (Figures 3 and 4) only show TMS-induced changes in activity, rather than the simple effect of load. It also would have been helpful to know whether the activity at higher frequencies, which are presumably more sensitive to the EMG, exhibited a similar dependence on load. Broadly similar concerns apply to earlier scalp-recorded electroencephalography studies that reported observing amplified gamma activity during the performance of WM tasks (eg, Haenschel et al, 2009; TallonBaudry et al, 1999).

\section{DISCLOSURE}

The authors declare no conflict of interest.

\section{REFERENCES}

Axmacher N, Schmitz DP, Wagner T, Elger CE, Fell J (2008). Interactions between medial temporal lobe, prefrontal cortex, and inferior temporal regions during visual working memory: a combined intracranial EEG and functional magnetic resonance imaging study. J Neurosci 28: 7304-7312.

Barr MS, Farzan F, Rusjan PM, Chen R, Fitzgerald PB, Daskalakis ZJ (2009). Potentiation of gamma oscillatory activity through repetitive transcranial magnetic stimulation of the dorsolateral prefrontal cortex. Neuropsychopharmacology 34: 2359-2367.

Haenschel C, Bittner RA, Waltz J, Haertling F, Wibral M, Singer W et al (2009). Cortical oscillatory activity is critical for working memory as revealed by deficits in early-onset schizophrenia. J Neurosci 29: 9481-9489.

Shackman AJ, McMenamin BW, Slagter HA, Maxwell JS, Greischar LL, Davidson RJ (2009). Electromyogenic artifacts and electroencephalographic inferences. Brain Topogr 21: 7-12.

Tallon-Baudry C, Kreiter A, Bertrand O (1999). Sustained and transient oscillatory responses in the gamma and beta bands in a visual short-term memory task in humans. Vis Neurosci 16: 449-459.

\footnotetext{
*Correspondence: Dr AJ Shackman, Laboratory for Affective Neuroscience, Waisman Laboratory for Brain Imaging and Behavor, University of Wisconsin-Madison, 1202 West Johnson Street, Madison, WI 53706, USA, Tel: + I 608358 5025, Fax: + I (608) 265-2875, E-mail: shackman@wisc.edu

Received 16 September 2009; accepted 17 September 2009
} 